\title{
The Characteristic Variations of the Eastward Drift Velocities of the Equatorial Plasma Bubbles in East Asia during High Solar Activity Period
}

\author{
Kang CHENG ${ }^{1}$ and Yinn-Nien HUANG ${ }^{2}$ \\ ${ }^{1}$ Lunping Observatory, Telecommunication Training Institute, Directorate General of Telecommunications, MOTC, \\ 180 Lunping, Kuanyin, Taoyuan, Taiwan, Republic of China \\ ${ }^{2}$ Directorate General of Telecommunications, MOTC, 31 Aikuo East Road, Taipei, Taiwan, Republic of China
}

(Received August 27, 1994; Revised March 15, 1995; Accepted March 24, 1995)

From January 1988 to December 1990, ionospheric total electron content depletions associated with amplitude scintillations observed simultaneously at two equatorial anomaly stations (Kaohsiung and Chihpen) have been used to investigate the eastward drift velocities of the equatorial plasma bubbles in East Asian region. It is found that there are considerable large variability of eastward drift velocities. The nocturnal variation pattern shows a tendency for the eastward drift velocities to decrease from early evening to presunrise hours. Seasonal variations show large eastward drift velocities in summer than in equinox. During midnight and postmidnight periods, eastward drift velocities decrease slightly with the increasing of magnetic activity.

\section{Introduction}

The ionospheric total electron content (TEC) depletions, also referred to as ionospheric plasma bubbles, associated with amplitude scintillations have been observed by many workers at equatorial stations. Similar ionospheric plasma bubbles were also observed at equatorial anomaly crest stations by Klobuchar et al. (1978) at Ascension Island (mag. lat. 195), by Koparkar and Rastogi (1984) at Bombay, India (mag. lat. $15^{\circ} \mathrm{N}$ ), and by Huang (1985) at Lunping, Taiwan (mag. lat. $\left.12^{\circ} \mathrm{N}\right)$. Plasma bubbles are localized depletion of ionization density in the nighttime equatorial ionosphere as observed in situ by satellite (Hanson and Sanatani, 1973; McClure et al., 1977) and rocket (Kelly et al., 1976; Morse et al., 1977) probes. The formation and dynamics of equatorial plasma bubbles have been studied experimentally and theoretically by many workers. It is now generally agreed that the postsunset plasma bubbles in the equatorial region are generated, initially on the bottomside of $F$ Layer, in association with the RayleighTaylor instabilities in the ionosphere. Once these plasma bubbles are triggered, the bubbles grow nonlinearly and rise upward into regions above the peak of $F$ layer extending to well over $1600 \mathrm{~km}$ in altitude by polarization $\boldsymbol{E} \times \boldsymbol{B}$ motion (e.g., Kelley and McClure, 1981; Ossakow, 1981 and references therein).

In the $F$ layer, neutral winds blowing across the magnetic field lines cause a slow transverse drift of the positive ions, perpendicular to both the winds and the magnetic field lines. This drift sets up a polarization electric field in the $F$ layer which can be discharged by currents flowing along magnetic field lines and through the $E$ region. During nighttime, the $E$ region conductivity is too small to close this circuit, so that polarization fields build up in the $F$ layer, causing the plasma to drift eastward with the wind (Rishbeth, 1971; Woodman, 1972; Abdu et al., 1985a). Plasma bubbles are also strongly field aligned along the magnetic flux tubes (Dyson and Benson, 1978; Weber et al., 1978; Aarons et al., 1980; Tsunoda, 1980). As the bubble moves from the bottomside of the equatorial ionosphere to higher altitudes, where the diffusion is rapid, plasma redistributes along the magnetic field line and causes the volume of the bubble to expand along the field line from the magnetic equator into both hemisphere north and south. This gives rise to the observation of the ionospheric bubbles moving apparently not only eastward but also poleward near the equatorial anomaly crest region (Huang, 1990). 
There are many reports regarding the nighttime equatorial plasma eastward drift velocities. $F$ region incoherent scatter radar measurements at the Jicamarca Radio Observatory (mag. dip. $2^{\circ} \mathrm{N}$ ) have provided extensive information on the equatorial bulk plasma velocity (Fejer et al., 1981, 1985, 1991). Using the radar interferometer technique, Kudeki et al. (1981) measured the eastward drift velocities over Jicamarca during strong spread- $F$ conditions. In Brazil (mag. dip. $26^{\circ} \mathrm{S}$ ), the plasma bubble eastward drift velocities were investigated by using the OI $6300 \mathrm{~A}$ airglow photometer measurements (Sobral et al., 1985) and the spaced VHF polarimeter systems (Abdu et al., 1985a). Based on the simultaneous recording of the telemetry signals $(4 \mathrm{GHz})$ transmitted from two geostationary satellites at Sikandarabad (mag. dip. $42^{\circ} \mathrm{N}$ ) and Chenglept (mag. dip $10.5^{\circ} \mathrm{N}$ ) satellite Earth stations, Dabas et al. (1992) estimated the eastward drift velocities of the plasma bubble in the India zone. In in-situ measurements, DE 2 satellite observations were used to study the characteristics of low-latitude zonal plasma drifts and the height variation of equatorial zonal drifts from the altitude of about 200 up to $2000 \mathrm{~km}$ (Maynard et al., 1988; Coley and Heelis, 1989). However, so far no one has reported the eastward drift velocities of equatorial plasma bubble over the East Asian region.

In order to study the ionospheric dynamics around East Asian equatorial anomaly crest region, total electron content and scintillation observations were recorded at three equatorial anomaly stations, including Lunping, Kaohsiung and Chihpen in Taiwan (Huang, 1988). The plasma bubble eastward drift velocities over the magnetic equator in the East Asian region have been determined by the simultaneous TEC depletion observations at two stations, Kaohsiung and Chihpen, which are located in the same geomagnetic latitudinal circle in the equatorial anomaly crest region. The nocturnal, seasonal, and magnetic activity dependence of the equatorial plasma bubble eastward drift velocities will be described in this paper. We hope that the results of this study can be used to model the neutral wind over the East Asian region.

\section{Observations}

Total electron content (TEC) and scintillation observations have been carried out at Lunping Observatory $\left(25.00^{\circ} \mathrm{N}, 121.17^{\circ} \mathrm{E}\right)$ since March 1977 by receiving the $136.1124-\mathrm{MHz}$ linear polarized beacon signal transmitted from the Japanese ETS-2 geostationary satellite (Huang, 1981). In order to investigate the spatial variations of total electron content and to determine the horizontal velocity vector of the movement of Traveling Ionospheric Disturbances and ionospheric irregularities, two more TEC stations were established at Kaohsiung $\left(22.64^{\circ} \mathrm{N}, 120.21^{\circ} \mathrm{E}\right)$ and Chihpen $\left(22.71^{\circ} \mathrm{N}, 121.04^{\circ} \mathrm{E}\right)$ in January 1986, as shown in Fig. 1 (Huang, 1988). The geomagnetic coordinates of the subionospheric points at 420 $\mathrm{km}$ altitude of these stations are at $12.3^{\circ} \mathrm{N}, 192.1^{\circ} \mathrm{E} ; 10.2^{\circ} \mathrm{N}, 192.1^{\circ} \mathrm{E}$; and $10.1^{\circ} \mathrm{N}, 191.4^{\circ} \mathrm{E}$, as indicated respectively by $P_{1}, P_{2}$ and $P_{3}$ in Fig. 1 . These subionospheric points form a right-angled triangle with the vertical side aligned parallel to the geomagnetic meridional line, and the horizontal side along the geomagnetic east-west direction. Due to the flux tube alignment properties of the plasma bubbles, the alignment of the stations of Kaohsiung and Chihpen provides a good opportunity to investigate the eastward drift velocities of the equatorial plasma bubbles. The apex altitudes defined as the equatorial crossing heights of the magnetic field lines passing through the $F$ region height $(420 \mathrm{~km})$ over Kaohsiung and Chihpen are about $800 \mathrm{~km}$. The TEC depletions detected at our equatorial anomaly region should represent the plasma bubble vertically extending up to $800 \mathrm{~km}$ above the equator, and hence those deduced eastward drift velocities are at the end of their growth phase.

Figure 2 shows a typical example of the eastward drift of the ionospheric bubble as manifested by TEC depletion and associated amplitude scintillation. The TEC depletion and the associated amplitude scintillation at Kaohsiung appear earlier than at Chihpen; and the TEC depletion observed at Chihpen is smaller than that at Kaohsiung showing eastward drift of the ionospheric bubble. From January 1986 to December 1990, those TEC depletions associated with scintillations simultaneously observed at Kaohsiung and Chihpen are selected to determine the eastward drift velocities of the equatorial plasma bubble. Monthly distributions of the occurrence of TEC depletions from 1986 to 1990 are shown in Fig. 3. The 


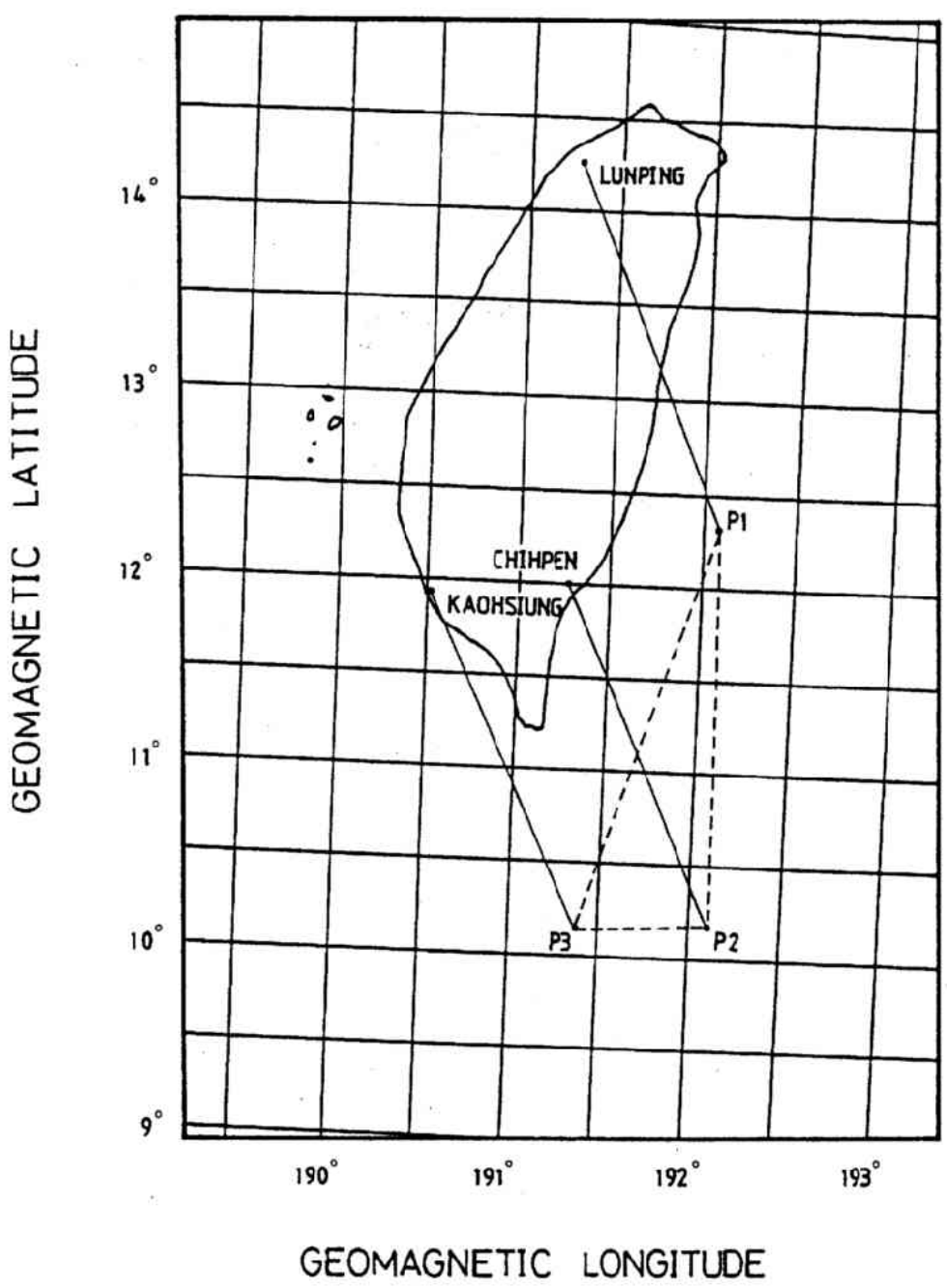

Fig. 1. Geomagnetic coordinate locations of the three spaced TEC polarimeters installed at Lunping, Chihpen, and Kaohsiung. $\mathrm{P}_{1}, \mathrm{P}_{2}$ and $\mathrm{P}_{3}$ represent the corresponding subionospheric points at $420 \mathrm{~km}$ height.

yearly mean sunspot numbers are also indicated in the parentheses for each year to represent the solar activity. As reported in the previous paper by Huang (1985), the occurrence of TEC depletion during low solar activity period is very rare. Most of the TEC depletions are observed during high solar activity period. The seasonal occurrence pattern exhibits two maxima in equinoxes (with the autumnal maximum larger than the vernal maximum), a shallow minimum in summer solstice, and a deep minimum in winter solstice. This TEC depletion occurrence pattern is in general agreement with the ionospheric scintillation pattern around East Asian region as reported by Aarons (1993) and also agrees with the solar terminator-magnetic meridian alignment theory proposed by Tsunoda (1985).

Since most of the TEC depletions were observed during high solar activity period (1988-1990), and a few TEC depletion occurred during low solar activity period (1986-1987), therefore, we only use the TEC depletion data observed during high solar activity period for the present study. For each case, the onset times at both stations are used to determine the time delay between the two. The eastward drift velocity of the plasma bubble is determined by dividing the longitudinal distance between the respective magnetic field line apexes over the magnetic equator by the time delay. 


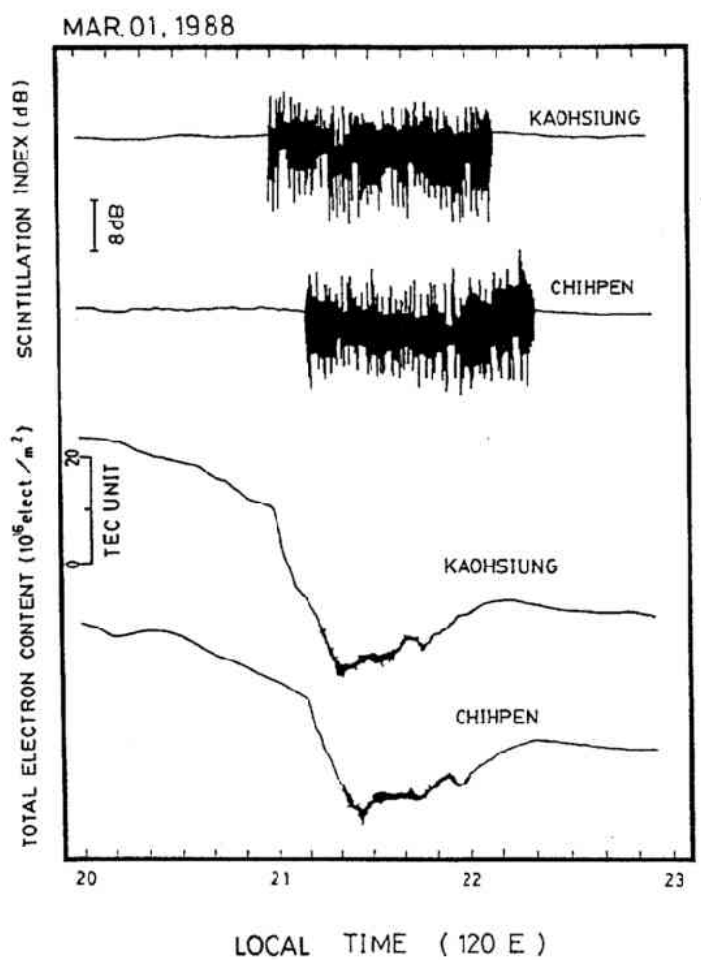

Fig. 2. Example of TEC depletion associated with amplitude scintillation observed simultaneously at Kaohsiung and Chihpen on March 1, 1988.

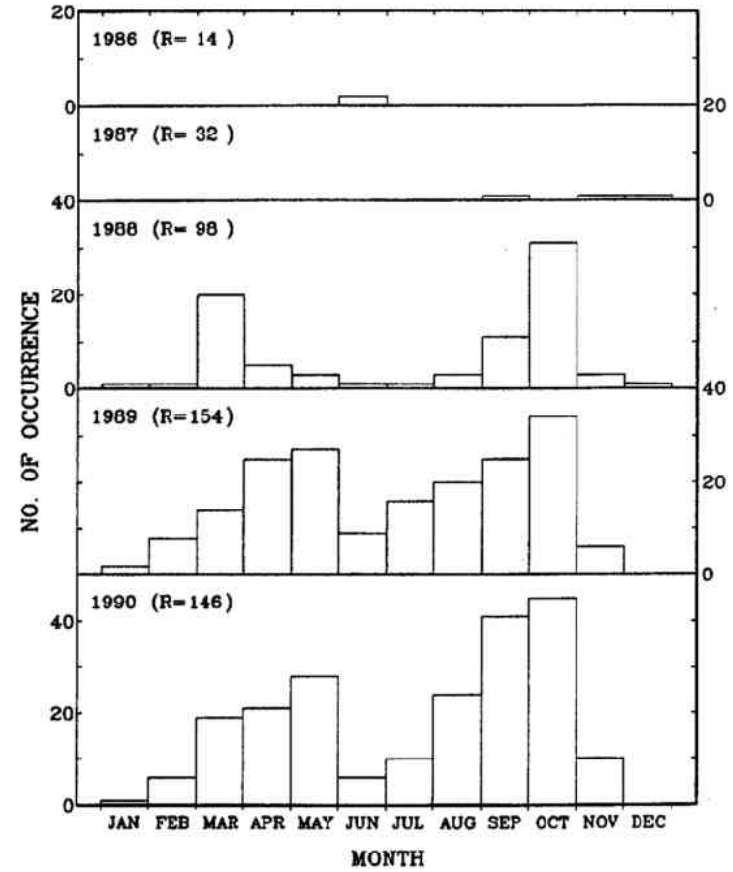

Fig. 3. Seasonal and solar cycle variations of the occurrence number of TEC depletion observed simultaneously at Kaohsiung and Chihpen. 


\section{Results and Discussion}

Nocturnal variations of the median eastward drift velocities for each season obtained for each hourly interval centered at half hour starting from 1900 to $0400 \mathrm{LT}$ are shown in Fig. 4. The symbol U represents a bin that contained three or less data points, and the corresponding median value might not be typical. The number of data sample (NO), and the median (MED), upper quartile (UQ), lower quartile (LQ) and quartile range $(\mathrm{QR})$ values of eastward drift velocities for each bin are presented in Table 1. Most of the TEC depletions were observed during equinoxes and around 2000 to $2300 \mathrm{LT}$. The quartile range values

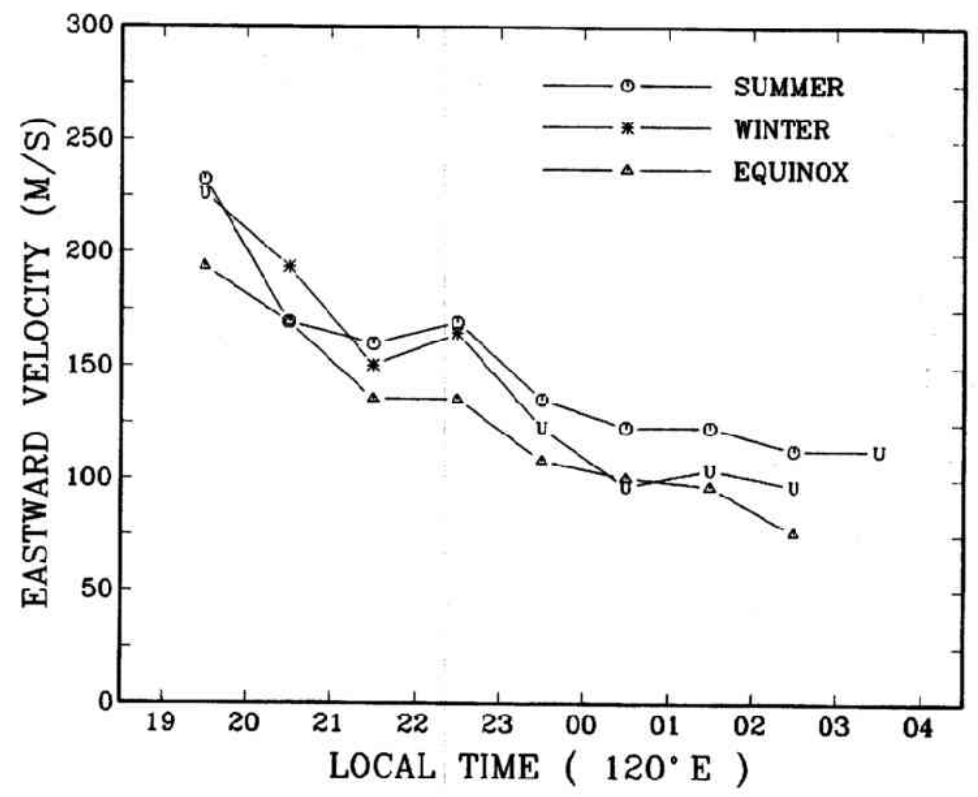

Fig. 4. Nocturnal variation of eastward drift velocities of ionospheric plasma bubble.

Table 1. The number of data sample (NO), and the median(MED), upper quartil(UQ), lower quartil (LQ), and quartil range (QR) values of eastward drift velocity $(\mathrm{m} / \mathrm{s})$ for each bin centered at half hour starting from 1900 to $0400 \mathrm{LT}$ under different seasons.

\begin{tabular}{|c|c|rrrrrrrrr|}
\hline \multicolumn{2}{|c|}{ Local Time (LT) } & $19-20$ & $20-21$ & $21-22$ & $22-23$ & $23-00$ & $00-01$ & $01-02$ & $02-03$ & $03-04$ \\
\hline \multirow{5}{*}{ Summer } & NO & 6 & 20 & 24 & 25 & 21 & 20 & 22 & 7 & 3 \\
& MED & 233 & 170 & 160 & 170 & 136 & 123 & 123 & 113 & 113 \\
& UQ & 452 & 226 & 182 & 194 & 160 & 151 & 136 & 123 & 118 \\
& LQ & 170 & 151 & 123 & 136 & 118 & 104 & 104 & 104 & 96 \\
& QR & 282 & 75 & 59 & 58 & 42 & 47 & 32 & 19 & 22 \\
\hline \multirow{5}{*}{ Winter } & NO & 3 & 11 & 9 & 6 & 3 & 1 & 3 & 3 & 0 \\
& MED & 226 & 194 & 151 & 165 & 123 & 97 & 104 & 97 & - \\
& UQ & 249 & 226 & 160 & 194 & 137 & - & 114 & 110 & - \\
& LQ & 175 & 170 & 128 & 113 & 123 & - & 92 & 86 & - \\
& QR & 74 & 56 & 32 & 81 & 14 & - & 22 & 24 & - \\
\hline \multirow{5}{*}{ Equinox } & NO & 33 & 67 & 61 & 39 & 28 & 18 & 33 & 12 & 0 \\
& MED & 194 & 170 & 136 & 136 & 109 & 101 & 97 & 76 & - \\
& UQ & 271 & 194 & 170 & 151 & 123 & 113 & 118 & 101 & - \\
& LQ & 194 & 151 & 123 & 104 & 90 & 85 & 71 & 51 & - \\
& QR & 77 & 43 & 47 & 47 & 33 & 28 & 47 & 50 & - \\
\hline
\end{tabular}


indicate that there are considerable large variations in the eastward drift velocities for each bin. Although the nocturnal variations of summer and winter show a small valley around 2100-2200 LT or a small peak around 2200-2300 LT, the nocturnal variation patterns show a high eastward drift velocities in the evening hours (1900-2000 LT) and decrease to a low eastward drift velocities in the postmidnight hours (02000300 LT). Since the occurrence of TEC depletion during winter time is very rare and the winter time drift velocities might not be typical, the seasonal variations of eastward drift velocities can only be determined during summer and equinoxes periods. In the early evening, there is no significant seasonal difference can be found. However after $2200 \mathrm{LT}$, in the late night to morning sectors, there exists a significant tendency for a larger drift in summer and a smaller drift in equinoxes. Although there are many papers published concerning the characteristics of equatorial plasma bubble eastward drift velocities, so far the seasonal variations of eastward drift velocities has only reported by Fejer et al. (1991). In Jicamarca, Fejer et al. (1991) reported the seasonal variations of the nighttime eastward plasma drift with largest during local winter and smallest during summer. This discrepancy implies that there exists a longitudinal difference of the seasonal variations of the equatorial zonal plasma drift. It is worthwhile for further study.

Using DE 2 satellite measurements, Coley and Heelis (1989) reported the average eastward plasma velocity in the 600 to $1000 \mathrm{~km}$ apex altitude range during high solar activity. The velocity measured during the nighttime period is reproduced in Fig. 5 for comparison. Due to the $90^{\circ}$ inclination of DE 2 satellite, the plasma velocities measured around midnight are taken during the equinoctial period. The local time decrease in the plasma velocity of our results after $2000 \mathrm{LT}$ is in agreement with the nocturnal pattern obtained by DE 2, except that after midnight, our velocities are higher than those of Coley and Heelis. In Fig. 5, we also plotted the eastward bulk plasma drift velocities reported by Fejer et al. (1991) using Jicamarca radar observations during the equinoctial period of high solar activity. Although, the Jicamarca data were taken mostly in the 300 to $400 \mathrm{~km}$ altitude range on non spread- $F$ nights, the local time decrease in bulk

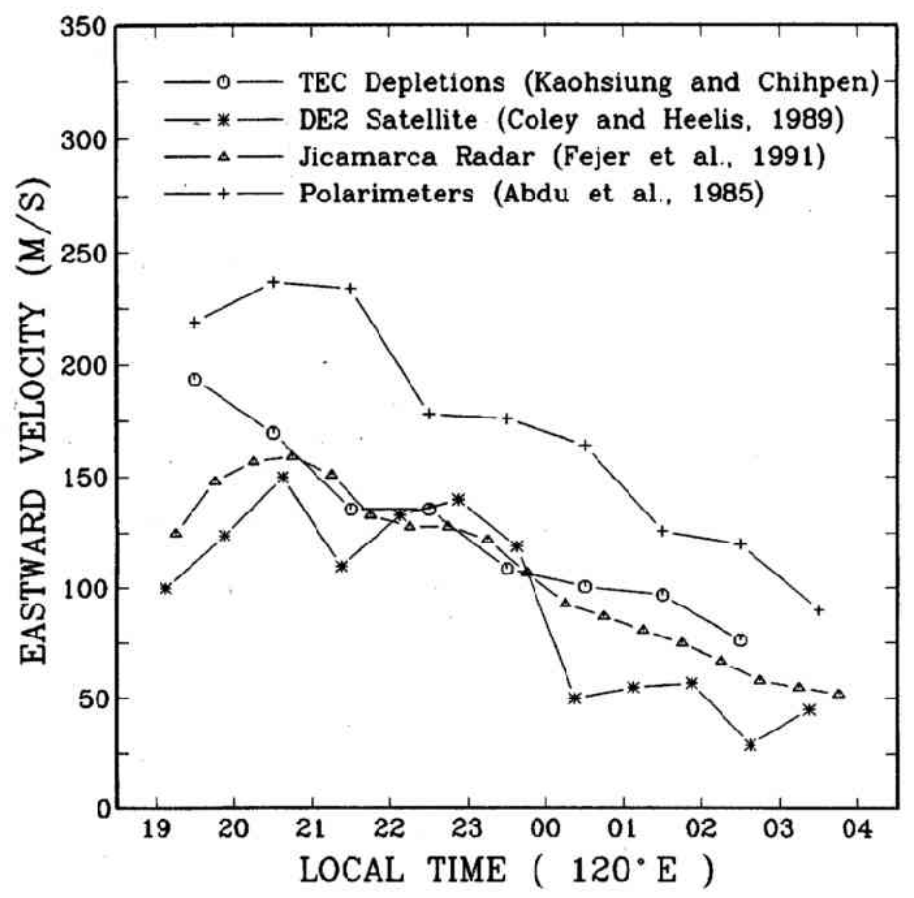

Fig. 5. Comparison between the equinoctial eastward drift velocities obtained in this study, with those measured by DE 2 satellite and by the Jicamarca radar. The summer-night eastward drift velocities measured by Polarimeters are also plotted for comparison. 
plasma velocity after $2000 \mathrm{LT}$ is in good agreement with the behavior at these hours in our results. During the summer time of high solar activity period, Abdu et al. (1985a) also reported the local time decrease of plasma bubble eastward drift after $2000 \mathrm{LT}$ at heights around $700 \mathrm{~km}$ over the equator (as also shown in Fig. 5).

Such a nocturnal decrease of eastward drift velocities after $2000 \mathrm{LT}$ can be explained in terms of the decrease of $F$ layer neutral wind through $F$ region dynamo. The neutral winds blowing across the magnetic field lines in the $F$ layer cause a slow transverse drift of the positive ions perpendicular to both the winds and the magnetic field lines. This drift sets up a polarization electric field in the $F$ layer which can be discharged by currents flowing along magnetic field lines and through the $E$ region. However, during nighttime, the $E$ region conductivity is too small to close this circuit, so that polarization fields build up in the $F$ layer, causing the nighttime $F$ layer plasma to drift eastward identically with the neutral wind (Rishbeth, 1971; Woodman, 1972; Abdu et al., 1985a). Using Fabry-Perot interferometer at Kwajalein Atoll, Sipler et al. (1983) provided an evidence showing that the nighttime $F$ region eastward neutral winds decrease from 2000 LT to presunrise hours.

From Fig. 5, it can be seen that the major discrepancy between our results with those reported by others appears around 1900-2000 LT. Our result shows highest value in this interval, whereas the DE 2 satellite data and the Jicamarca Radar data in Peru show that the value around 1900-2000 LT is smaller than the value around 2000-2100 LT. Besides, the paper of Abdu et al. (1985a) shows that even during summer time, the value in 1900-2000 LT is also smaller than the value in 2000-2100 LT over the equator in Brazil. However, on the other hand, Dabas et al. (1992) reported that the value around 1900-2000 LT is larger than the value around 2000-2200 LT for the observation at Chenglepet (mag. dip $10.5^{\circ} \mathrm{N}$ ) around $400 \mathrm{~km}$ altitude over the equator in India. Such kind of discrepancy also suggests longitudinal difference of the equatorial zonal plasma drift.

As previously mentioned, most of the TEC depletions are observed during equinoxes and there also exists a seasonal dependence in the eastward drift velocities. Therefore, we only use the data derived in equinoctial period to investigate the magnetic activity dependence of the eastward drift velocities. These data are separated into two groups representing $K_{p} \leq 2+$ and $K_{p}>2+$, and the results of magnetic dependence are presented in Fig. 6 . The vertical bars represent the quartile ranges for each bin. It can be seen that the premidnight eastward drift velocities show very little variation with magnetic activity. Using Jicamarca Radar data, Fejer et al. $(1981,1991)$ also reported that the premidnight $F$ region drifts are essentially independent of magnetic activity. The observations from spaced VHF polarimeter measurements of TEC depletion during spread $F$ conditions by Abdu et al. (1985b) in Brazil have shown that the plasma eastward drift velocities do not change when changes in simultaneous $K_{p}$ values are considered. However, there exists a clear tendency for the eastward drift velocities enhanced maily in the premidnight hours immediately following magnetic disturbances. On the other hand, Sobral et al. (1985) reported that the premidnight drift velocities obtained from airglow photometer measurements vary in varying degrees with geomagnetic activity. The result of this paper confirms that the premidnight zonal velocities do not always correspond to the ambient plasma velocities as suggested by Fejer et al. (1991).

The quartile ranges shown in Fig. 6 indicate that there are considerable large variability of eastward drift velocities even during magnetic quiet conditions. A large data base is necessary to determine the magnetic activity dependence. Nevertheless, during midnight and postmidnight periods, although not very significant, there is a tendency that the eastward drift velocities decrease slightly with the increasing of $K_{p}$ index. This is consistent with the ionospheric disturbance dynamo electric field effects, which is investigated in detail by Blanc and Richmond (1980). During magnetic disturbance period, the polar ionosphere is greatly disturbed by particle bombardment, electric currents and electric fields. Both the particle bombardment and joule dissipation heat the auroral atmosphere and drive substantial equatorward disturbance winds during magnetic disturbance period. The transport of angular momentum by these equatorward winds gives rise to westward winds in mid- and low-latitudes, which drive equatorward Pedersen currents. Charge accumulates at the equator, giving rise to a poleward electric field and hence to westward ion drifts. It is noted that during disturbed period, Ganguly et al. (1987) showed a westward 


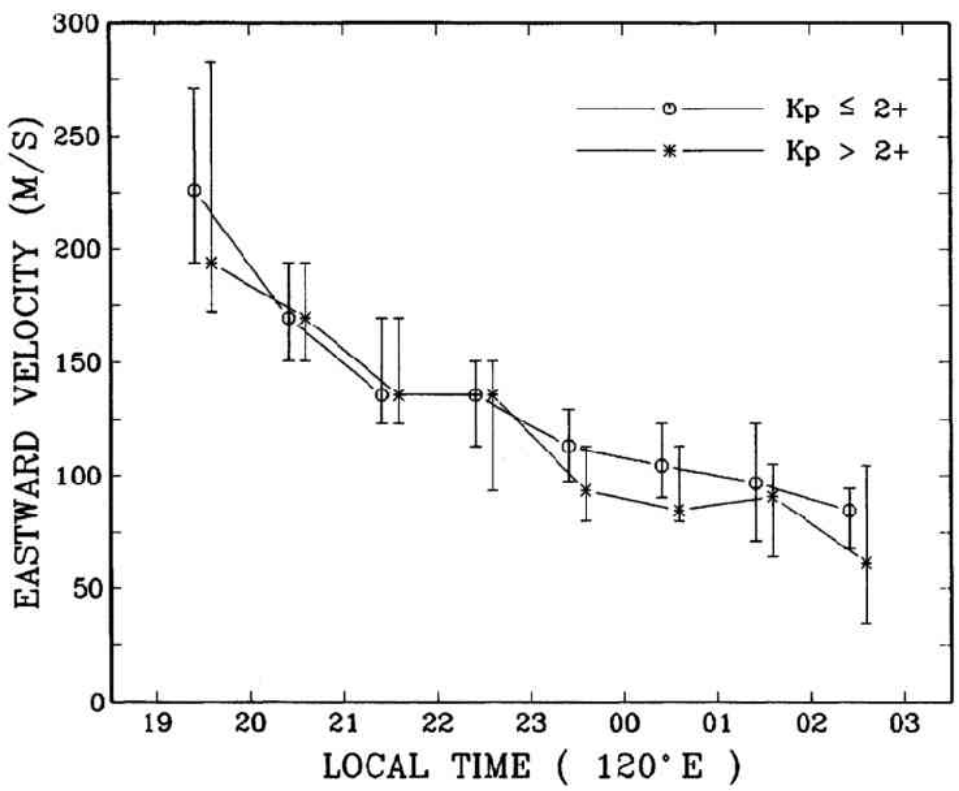

Fig. 6. Magnetic activity dependence of the eastward drift velocity of ionospheric plasma bubbles. The vertical bars indicate the quartile ranges for each bin.

velocity (with largest amplitude in the late night-early morning sector) in the daily average zonal drifts above Arecibo (mag. lat. $30^{\circ} \mathrm{N}$ ), which is expected from the disturbance dynamo process.

\section{Conclusions}

By simultaneous observations of the ionospheric total electron content depletions associated with amplitude scintillations at two stations (Kaohsiung and Chihpen) located in the same magnetic latitudinal circle near the equatorial anomaly crest region, the eastward drift velocities of the equatorial plasma bubbles in the East Asian region during high solar activity period has been investigated. The eastward drift velocities observed in this paper correspond to the velocities map to the altitude of about $800 \mathrm{~km}$ over the magnetic equator. It is found that the eastward drift velocities have large statistical fluctuations. A large data base of total electron content depletions is necessary to determine the characteristics of eastward drift velocities. Although not very significant, the major findings of the present study are: (1) The nocturnal variation shows a tendency for the eastward drift velocities to decrease from early evening to presunrise hours, (2) seasonal variations show large eastward drift velocities in summer than in equinox, and (3) the late night and postmidnight eastward drift velocities decrease slightly with the increase of magnetic activity.

The Editor thanks S. Watanabe and another referee for their assistance in evaluating this paper.

\section{REFERENCES}

Aarons, J., The longitudinal morphology of equatorial F-layer irregularities relevant to their occurrence, Space Sci. Rev., 63, 209$243,1993$.

Aarons, J., J. P. Mullen, H. E. Whitney, and E. M. MacKenzie, The dynamics of equatorial irregularity patch formation, motion, and decay, J. Geophys. Res., 85, 139-149, 1980.

Abdu, M. A., I. J. Kantor, I. S. Batista, and E. R. de Paula, East-west plasma bubble irregularity motion determined from spaced 
VHF polarimeters: Implications on velocity shear in the zonal $F$ region bulk plasma motion, Radio Sci., 20, 111-122, 1985a. Abdu, M. A., I. S. Batista, J. H. A. Sobral, E. R. de Paula, and I. J. Kantor, Equatorial, ionospheric plasma bubble irregularity occurrence and zonal velocities under quiet and disturbed conditions, from polarimeter observations, J. Geophys. Res., 90, 9921-9928, 1985b.

Blanc, M. and A. D. Richmond, The ionospheric disturbance dynamo, J. Geophys. Res., 85, 1669-1686, 1980.

Coley, W. R. and R. A. Heelis, Low-latitude zonal and vertical ion drifts seen by DE 2, J. Geophys. Res., 94, 6751-6761, 1989.

Dabas, R. S., P. K. Banerjec, S. Bhattacharya, B. M. Reddy, and J. Singh, Study of equatorial plasma bubble dynamics using GHz scintillation observations in the Indian sector, J. Atmos. Terr. Phys., 54, 893-901, 1992.

Dyson, P. L. and R. F. Benson, Topside sounder observations of equatorial bubbles, Geophys. Res. Lett., 5, 795-798, 1978.

Fejer, B. G., D. T. Farley, C. A. Gonzales, R. F. Woodman, and C. Calderon, F region east-west drifts at Jicamarca, J. Geophys. Res., 86, 215-218, 1981.

Fejer, B. G., E. Kudeki, and D. T. Farley, Equatorial $F$ region zonal plasma drifts, J. Geophys. Res., 90, 12249-12255, 1985.

Fejer, B. G., E. R. de Paula, S. A. Gonzalez, and R.F. Woodman, Average vertical and zonal $F$ region plasma drifts over Jicamarca, J. Geophys. Res., 96 13901-13906, 1991.

Ganguly, S., R. A. Behnke, and B. A. Emery, Average electric field behavior in the ionosphere above Arecibo, J. Geophys. Res., 92, 1199-1210, 1987.

Hanson, W. B. and S. Sanatani, Large $N i$ gradients below the equatorial $F$ peak, J. Geophys. Res., 78, 1167-1173, 1973.

Huang, Y. N., Some results of ionospheric total electron content and scintillation observation at Lunping, Proceedings of the Effect of the Ionosphere on Radiowave Systems, paper 2-9, U.S. Government Printing Office, Washington, D.C., 1981.

Huang, Y. N., Ionospheric electron content depletion associated with amplitude scintillation at the equatorial anomaly crest region, J. Geophys. Res., 90, 4333-4339, 1985.

Huang, Y. N., Geomagnetic and ionospheric studies in Taiwan, J. Electr. Eng. 31, 281-294, 1988.

Huang, Y. N., Drift motion of ionospheric bubbles at the equatorial anomaly crest region, J. Geophys. Res., 95, 4297-4301, 1990.

Kelley, M. C. and J. P. McClure, Equatorial Spread-F: A review of recent experimental results, J. Atmos. Terr. Phys., 43, 427435, 1981.

Kelley, M. C., G. Haerenddel, H. Kappler, A. Valenzuela, B. B. Balsley, D. A. Carter, W. L. Ecklund, C. W. Carlson, B. Hausler, and R. Torbert, Evidence for a Rayleigh-Taylor type instability and upwelling of depleted density regions during equatorial spread F, Geophys. Res. Lett., 3, 448-450, 1976.

Klobuchar, J. A., J. Aarons, E. Weber, L. Lucena, and M. Mendillo, Total electron content changes associated with equatorial irregularity plumes, paper presented at National Radio Science Meeting, Union Radio Sci. Int., Boulder, Colo., Nov. 6-9, 1978.

Koparkar, P. V. and R. G. Rastogi, Faraday fluctuations and amplitude scintillations at low latitude, paper presented at 7 th International Symposium on Equatorial Aeronomy, Univ. of Hong Kong, Hong Kong, 1984.

Kudeki, E., B. G. Fejer, D. T. Farley, and H. M. Ierkic, Interferometer studies of equatorial $F$ region irregularities and drifts, Geophys. Res. Lett., 8, 377-380, 1981.

Maynard, N. C., T. L. Aggson, F. A. Herrero, and M. C. Liebrecht, Average low-latitude meridional electric fields from DE 2 during solar maximum, J. Geophys. Res., 93, 4021-4037, 1988.

McClure, J.P., W. B. Hanson, and J.H. Hoffman, Plasma bubbles and irregularities in the equatorial ionosphere, J. Geophys. Res., 82, 2650-5656, 1977.

Morse, F. A., B. C. Edgar, H. C. Koons, C. J. Rice, W. J. Heikkila, J. H. Hoffman, B. A. Tinsley, J. D. Winningham, A. B. Christensen, R. F. Woodman, J. Pomalaza, and N. R. Teixeira, Equion, an equatorial ionospheric irregularity experiment, J. Geophys. Res., 82, 578-592, 1977.

Ossakow, S. L., Spread-F theories: A review, J. Atmos. Terr. Phys., 43, 437-452, 1981.

Rishbeth, H., Polarization fields produced by winds in the equatorial F-region, Planet. Space Sci., 19, 357-369, 1971.

Sipler, D. P., M. A. Biondi, and R. G. Roble, $F$-region neutral winds and temperatures at equatorial latitudes: measured and predicted behavior during geomagnetically quiet conditions, Planet. Space Sci., 31, 53-66, 1983.

Sobral, J. H. A., M. A. Abdu, and Y. Sahai, Equatorial plasma bubble eastward velocity characteristics from scanning airglow photometer measurements over Cachoeira Paulista, J. Atmos. Terr. Phys., 47, 895-900, 1985.

Tsunoda, R. T., On the spatial relationship of $1-\mathrm{m}$ equatorial spread $F$ irregularities and plasma bubbles, J. Geophys. Res., 85, $185-190,1980$.

Tsunoda, R. T., Control of the seasonal and longitudinal occurrence of equatorial scintillations by the longitudinal gradient in integrated $E$ region Pedersen conductivity, J. Geophys. Res., 90, 447-456, 1985.

Weber, E. J., J. Buchau, R. H. Eather, and S. B. Mende, North-south aligned equatorial airglow depletions, J. Geophys. Res., 83, $712-716,1978$.

Woodman, R. F., East-west ionospheric drifts at the magnetic equator, Space Res., 12, 968, 1972. 